\title{
Antenatal Detection of Conjoined Twin
}

\author{
Sharma UK' ${ }^{1}$, Dangol A ${ }^{2}$, Chawla $C^{2}$, Shrestha $D^{3}$ \\ 'Department of Radiodiagnosis, Kathmandu Medical College. \\ ${ }^{2}$ Department of Obs/Gym, ${ }^{3}$ Department of Radiodiagnosis, Kathmandu University School of Medical Sciences.
}

\begin{abstract}
Conjoined twin is a sporadic event with prevalence of 1 in 50000 to 1000000 birth. Incomplete division of embryonic disc results in conjoined twin. Ultrasound plays a major role for early detection and proper obstetric management. A case of cephalothoracopagus conjoined twin was detected at 20 weeks pregnancy in a primigravida woman by antenatal ultrasound. The pregnancy was terminated after proper counseling, despite the need to save the baby, as multidisciplinary team to separate the twins was not available.
\end{abstract}

Key Words: Antenatal diagnosis, Conjoined twin, Ultrasound.

\section{INTRODUCTION}

Conjoined twin or Siam is a rare occurrence, which results when an embryo starts to divide, but fails to complete the process. Early detection is essential for the prognosis, obstetric management and treatment planning. For this ultrasound plays a vital role. Prenatal diagnosis of conjoined twins is difficult and was rarely accomplished prior to the advent of sonography. Prenatal recognition of conjoined twins and precise characterization of the malformation are required for optimal obstetric management. When severe forms are diagnosed prior to 24 weeks, pregnancy termination via vaginal delivery can be considered. Here, we present a case of cephalothoracopagus conjoined twin diagnosed antenatally at 20 weeks of gestational age.

\section{CASE REPORT}

A 28-years old female, primigravida presented for the routine antenatal ultrasound examination at 20 weeks of pregnancy. The pregnancy was precious because she had conceived after six year of primary infertility. She had no family history of multiple pregnancy or child with congenital abnormality. On ultrasound examination twins with joined heads, necks and chests but with separate abdomen, arms and legs were seen (Figure 1). The fetus shared the brain, but hearts were separate. Head circumference corresponded to 24 weeks, where as femur length correspond to 20 weeks of gestational age. The pregnancy was terminated after proper parental counseling. The babies were both having male external genitalia and they had joined heads, necks and chest with separate abdomen, pelvis, upper and lower limbs (cephalothoracopagus) consistent with ultrasound findings (Figure 2).

\section{DISCUSSION}

Conjoined twinning is a very rare abnormality, which occurs in one of every 100 sets of monozygotic twins

\author{
Correspondence: \\ Dr. Umesh Kumar Sharma \\ Department of Radiodiagnosis \\ Kathmandu Medical College \\ Sinamangar, Kathmandu, Nepal. \\ E-mail: dr_uksharma@yahoo.com
}


Table 1. Types of conjoined twins

Inferior conjunction - lower body is single or twins joined by some lower portion of body

Diprosopus - two faces with one head and body

Dicephalus - two heads with one body

Ischiophagus - joined by inferior sacrum and coccyx

Superior conjunction - upper body is single or twins joined by some upper portion of body

Dipygus - single head, thorax, abdomen two pelvis and four legs

Syncephalus - facial fusion with or without thoracic fusion

Craniophagus - joined at head

Middle conjuction - fusion of mid portion of the body, separate above and below

Thoracophagus - thoracic fusion

Omphalophagus - joined from umbilicus to xiphoid cartilage

Thoraco-omphalophagus - thoracic and abdominal fusion

Rachiphagus - vertebral fusion above sacrum

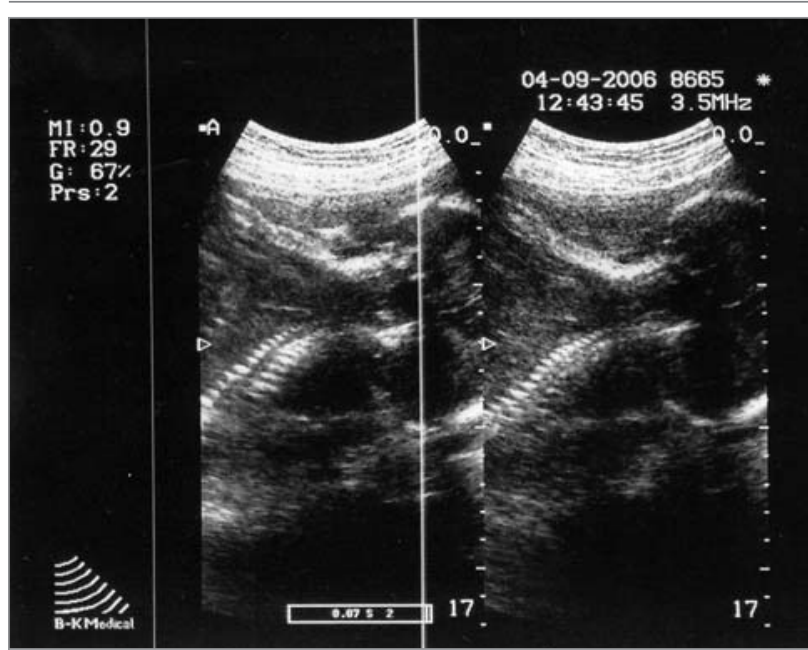

Figure 1. Ultrasound showing fused head, neck and chest of the twin

and in one of every 50,000 to 100,000 births. ${ }^{1}$ It occurs only in monochorionic monoamniotic twins without any known associations. Division of the embryonic disc after day eight postconceptions results in the formation of two embryos within a single amnion and a single chorion. Incomplete division of the embryonic disc results in conjoined twins. Division of the embryonic disc after 13 post conception is usually incomplete, resulting in varying degrees of fusion of the embryos. ${ }^{1}$

Conjoined twins are categorized by a set of adjectives ending with the suffix "pagus" from the greek word for "fixed". The most common form of conjoined twin is fusion of the anterior thorax and/or abdomen (referred to as thoracopagus, omphalopagus, and thoracoomphalopagus) which altogether constitute $70 \%$ of conjoined twins. ${ }^{2,3}$ Sacral (pyopagus), pelvic (ischiopagus),

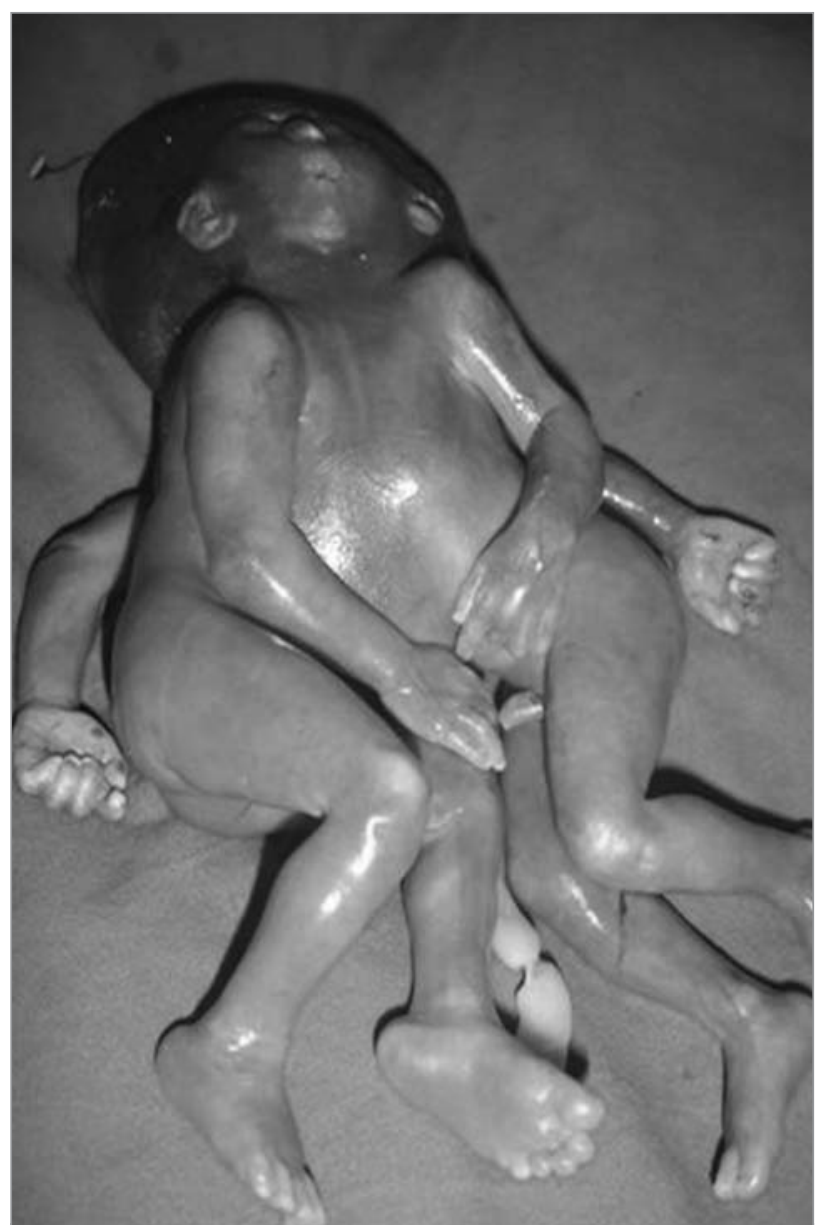

Figure 2. Photograph of the conjoined twin

and cranial (craniopagus) fusions are less common. ${ }^{4}$ Asymmetric forms known as heterogenous are exceedingly rare and have a parasitic attachment of a variably sized portion of anatomy attached to or even within any region of the body. ${ }^{5} \mathrm{~A}$ complete classification 
system developed by Guttmachem and Nichols is listed in Table $1 .{ }^{6}$ They are classified according to their most prominent site of connection.

Conjoined twins should be suspected in all monochorionic and monoamniotic twin pregnancies, and careful ultrasound assessment is advocated to rule out the sharing of fetal parts or organs. The major role of ultrasound is to detect and analyze the extent to which the organs are shared so that a reasonable assessment of surgical separability can be made. The index of suspicion of conjoined twin should increase if the twins maintain a constant and often unusual relative position and more together, if the neck and head are constantly hyperextended. ${ }^{4}$ in our case, there was no difficulty in identifying the conjoined twin on antenatal ultrasound. The twin had fused head, chest with separate abdomen, pelvis and limbs. The heart is always involved in the conjoinment, some thoracopagus twin have two separate hearts in a single pericardium (heart sac), while others share a single. In our case two separate hearts were seen. If surgical separation and viability appear possible without any major associated malformations based on ultrasound, cesaerean section is indicated to prevent perinatal fetal and maternal injury. The limitation of ultrasound is that a relatively small zone of fusion may not be detected and with a extreme degree of fusion, the twins may be mistaken for a singleton. ${ }^{5}$ Ultrafast Magnetic Resonance Imaging (MRI) can provide image quality superior to two dimensional ultrasonograpy and should be considered an adjunct to ultrasound for antenatal characterization of some anomalies. ${ }^{7}$ Ultrafast MRI provides excellent contrast with cerebrospinal fluid between the brain and spinal cord. Compared to ultrasonography, ultrafast MRI facilitates more precise visualization of antenatal brain characterization and spinal cord anomalies.

The mortality of conjoined twin is very high. ${ }^{5}$ Separation of conjoined twin is another great challenge and involves multidisciplinary team, the prognosis is determined by underlying anatomy. ${ }^{4,8}$ Early diagnosis and precise characterization is vital for proper obstetric and postnatal planning. This case highlights the crucial role of ultrasound in terms of early detection, proper intervention as well as counseling of the patient to reduce the psychological trauma.

\section{REFERENCES}

1. Finberg HJ. Ultrasound evaluation in multiple gestation. In Callen's ultrasonograpy in obstetrics and gynecology: Harcourt publishers $3^{\text {rd }}$ edi. 1194; chapter 8:121-124

2. Pretorins DH, Mahony BS. Twin gestations. In Nyberg ultrasound of fetal anomalies: Text and Atlas. Chicago, year book medical publishers 1990,592-622.

3. Filly RA, Goldstein RB, Callen PW. Monochorionic twinning: sonographic assessment. AJR 1990;154:459-469.

4. Levic CS, Lynos EA, Martel MJ. Sonography of multifetal pregnancy. In Rumack' diagnostic ultrasound: St Louis, Mosby-year book Inc 2005; chapter 35:1209-10.

5. Shah DS, Tomr G, PreetKiran, Prajapati H. Conjoined twins - report of two cases. Ind J Radiol Img 2006, 16:2L199-201.

6. Guttmacher AF, Nichols 131,. Teratology of conjoined twins. Birth Defects 1967: 3.3-9.

7. Ayhan Özkur, Mehmet Karaca, Ahmet Göçmen, Metin Bayram, Akif Sirikci. Cephalopagus conjoined twins presented with encephalocele: diagnostic role of ultrafast MR imaging. Diagn Interv Radiol 2006; 12:90-92.

8. Miller D, Colobani P, Buck JR, Dudgeon DL, Haller JA. New techniques in the diagnosis and operative management of Siamese twins. Journal of pediatric surgery 1983; 18(4):373376. 